\title{
REABILITAÇÃO NOMENCLATURAL E TAXONÔMICA DE VIROLA BICUHYBA (SCHOTT) WARB. (MYRISTICACEAE)
}

\author{
William A. Rodrigues'
}

Recebido em 07/04/1998. Aceito em 24/11/1998

\begin{abstract}
RESUMO - (Reabilitação nomenclatural e taxonômica de Virola bicuhyba (Schott) Warb. (Myristicaceae)). Esta nota trata da reabilitacão da Miristicácea Virola bicuhyba (Schott) Warb., designação de lectótipo e sinonimização tanto de Virola oleifera (Schott) A.C. Smith como de Bicuiba oleifera (Schott) de Wilde.
\end{abstract}

Palavras-chave - Myristicaceae, Virola bicuhỵba, reabilitação, sinonimização, lectotipificação

ABSTRACT - (Nomenclatural and taxonomic rehabilitation of Virola bicuhyba (Schott) Warb. (Myristicaceae)). This note deals with the rehabilitation of the Myristicaceous Virola bicuhyba (Schott) Warb., designation of lectotypes and sinonimization of both V. oleifera (Schott) A. C. Smith and Bicuiba oleifera (schott) de Wilde.

Key words - Myristicaceae; Virola bicuhyba; nomenclatural and taxonomic rehabilitation, synonimization, lectotypification

\section{Introdução}

A bicuíba é uma das essências florestais mais características da paisagem da floresta ombrófila da costa atlântica do sul e sudeste do Brasil. Desde a criação do nome proposto por Schott, em 1827, ela era conhecida cientificamente como Myristica bicuhyba, passando para Virola bicuhyba, em 1897, com o magnífico trabalho de revisão da família feito por Warburg. Em 1937, Smith, no seu tratamento taxonômico das Miristicáceas americanas, reduziu-a a sinônimo de V. oleifera (Schott) A.C. Smith. Sem melhor análise da questão nomenclatural da espécie, foi, desde então, este último nome o adotado por vários botânicos, entre eles Custódio Filho (1983), Hatschbach (1972), Reitz (1968), Rodrigues (1980), Uphof (1959), enquanto outros, como Machado (1949), Mello (1950), Schultes \& Holmstedt (1971) continuaram empregando corretamente $V$. bicuhyba como nome legítimo, ignorando ou não fazendo comentário algum sobre o outro sinônimo. Rizzini (1971) adotou a combinação proposta por Smith, porém esclarecia que $V$. bicuhyba era o nome usual no país. Mais recentemente, Wilde

Universidade Federal do Paraná, ICB, Coordenadoria de Pós-Graduação em Botânica, Centro Politécnico, Jardim das Américas, C.Postal 19031, CEP 81531-970. Curitiba. PR. Brasil 
(1991) propôs para o táxon em questão o novo gênero Bicuiba para acomodar a espécie monotípica, B. oleifera.

Por ocasião da preparação do manuscrito sobre as Miristicáceas para a Flora do Estado de São Paulo, tive oportunidade de rever mais atentamente a questão nomenclatural da espécie em tela, que passo a discutir em seguida.

\section{Discussão}

O nome Myristica oleifera, apresentado provisoriamente (sic: interim) por Schott em 1823, não foi posteriormente reconhecido por ele mesmo, que o substituiu, inexplicavelmente, por $M$. bicuhyba, em 1827, sem fazer qualquer justificativa sobre esse procedimento.

Em nenhum dos protólogos desses nomes, havia qualquer menção direta ou indireta de material botânico colhido ou mesmo de uma ilustração dos táxons em questão. Segundo o Art. 37.1 do Código Internacional de Nomenclatura Botânica - Código de Tóquio (Greuter et al. 1994), mesmo que o tipo eventualmente não tenha sido citado no protólogo, isto não invalida, de modo algum, um táxon novo proposto, sẻ publicado antes de $1^{\circ}$ de janeiro de 1958. No entanto, segundo o Dr. Jefferson Prado (comunicação pessoal), a indicação do tipo da espécie válida está na introdução do apêndice do trabalho de Schott (1827), onde esse autor menciona que todo o material-tipo de seus novos táxons foram colhidos por ele no Brasil, no período de 1817-1818. Infelizmente, não tive acesso, pessoalmente, a essa parte do trabalho.

Warburg (1897), baseando-se no nome legítimo de Schott, transferiu-o acertadamente para Virola bicuhyba, citando M. oleifera apenas como nome inválido. V. bicuhyba foi durante muito tempo o nome adotado até quando Smith (1937) o sinonimizou, legitimando a combinação $V$. oleifera $(=M$. oleifera $)$, admitindo que o basiônimo desta espécie era a que tinha prioridade e apresentava melhor descrição botânica, embora proposto provisoriamente por seu autor original. Conforme já mencionado anteriormente, essa resolução de Smith vai de encontro ao Art.34.1(b) do referido Código de Tóquio (loc.cit.), que prescreve taxativamente que "A name is not validly published.... (b) when it is merely proposed in anticipation of the future acceptance of the group concerned, or of a particular circumscription, position, or rank of the group (so called provisional name)...."

Recentemente, foi proposto por Wilde (1991) o gênero monotípico Bicuiba, indicando como espécie-tipo Bicuiba oleifera (Schott) de Wilde (=Myristica oleifera Schott). É uma proposta bastante discutível e que requereria melhores estudos, razão por que prefiro sinonimizá-lo. As principais características diferenciais do novo gênero assinaladas por ele existem, indistintamente, em várias outras espécies conhecidas dentro do gênero Virola, não sendo suficientemente significativas para separar taxonomicamente os dois gêneros. Estudos anteriores feitos por Carreira (1985) e Braga (1992) não encontram nada de particular na espécie em discussão que a distinguisse respectivamente pelo pólen ou anatomia foliar dos outros táxons afins do mesmo gênero. Além disto, do ponto de vista nomenclatural, o novo gênero não poderia, eventualmente, ser aceito por se basear numa espécie inválida, portanto, contrário ao Artigo 42.1 do Código de Tóquio. 
Em face do retro-exposto e com base nas evidências nomenclaturais e taxonômicas, o autor se sente no dever de propor a reabilitação de Virola bicuhyba (Schott) Warb., reduzindo os outros táxons a sinônimos, conforme o tratamento taxonômico a seguir:

Virola bicuhyba (Schott) Warb., Ber. Pharm. Ges.: 225. 1892, hipônimo; Ber. Deutsch. Bot. Ges. 13: 92. 1895; Nova Acta Acad. Leop.-Carol 68: 194, t. 6, f.1, 5 e 6. 1897.

Myristica bicuhyba Schott in Sprengel, Syst. Veg. (Cur. Post.), Appendix, 4 (2): 409. 1827. Tipo: Brasil, Rio de Janeiro, 1817-1818, fl., Schott 4559 (holótipo W, destruído). Lectótipo: designado por Rodrigues (1980): Schott 4559 (M; isolectótipos: B, destruído; BR (in Herb. Martius), n. v.; G, US; F foto 19100).

Myristica oleifera Schott interim, in: I. Oken, Isis oder Encyclopädische Zeitung 12-13: 1050. 1823. nom. inval.

Virola bicuhyba var. schenckii Warb., Ber. Pharm. Ges.: 228, f. 13. 1892, hipônimo; Warb. Nova Acta Acad. Leop.-Carol. 68: 206, t 6, fig. 2-4. 1897. Lectótipo aqui designado: Brasil, Santa Catarina, Itajaí, s. data, fl. Fr: Müller s.n.. (Ex Herb. R n. 61015; holossíntipo: B, destruído, K). Outros sintipos: Brasil, Santa Catarina. Blumenau, s.data, fr. Schenk 287. (B, destruído); Brasil, s. localidade, fr. Sello s.n. (B, destruído).

Virola oleifera var. schenckii (Warb.) Uphof in Engl. \& Prantl., Nat. Pflranzenfam. $2^{a}$ ed., 17a (2): 207. 1959.

Palala bicuhyba (Schott) Kuntze, Rer. Gen. Pl. 2: 567. 1891. nom. inval.

Virola araujovii Warb., Nova Acta Acad. Leop.-Carol. 68: 208, t. 7, f. 1-3. 1897. Tipo: Brasil, Minas Gerais, Rio Novo, set. 1889, fl. Araujo s.n. (holótipo B, destruído). Lectótipo: designado por Rodrigues (1980): Araujo s.n. (Ex Herb. R n. 61012).

Virola oleifera (Schott) A.C. Smith, Brittonia 2(5): 488. 1937. syn. nov.

Bicuiba oleifera (Schott) de Wilde, Beitr. Biol. Pflanzen 66: 121.1991. nomen non forte rite publicatum.

\section{Agradecimentos}

$\mathrm{O}$ autor agradece ao Dr. Jefferson Prado pelas sugestões apresentadas e ao $\mathrm{CNPq}$ pelo apoio financeiro.

\section{Referências bibliográficas}

Braga, M. M. N. 1992. Anatomia foliar de Virola Aublet (Myristicaceae). Boletim do Museu Paraense Emílio Goeldi, série Botânica 8(1): 57-142.

Carrera. L. M. M. 1985. Estudo polínico das espécies de Virola Aublet (Myristicaceae) do Brasil. Boletim do Museu Paraense Emilio Goeldi, série Botânica 2(1): 29-76.

Custódio Filho, A. 1983. Flora fanerogâmica da Reserva do Parque Estadual das Fontes de Ipiranga (São Paulo, Brasil). 4. Myristicaceae. Hoehnea 10: 24-25.

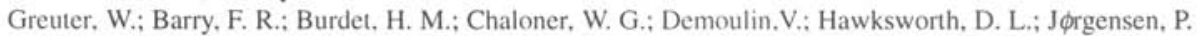
M.; Nicolson, D. H.; Silva, P. C.; Trehane, P \& McNeill, J. (eds.) 1994. International Code of Botanical Nomenclature (Tokyo Code). Regnum Vegetabile 131: 1-389.

Hatschbach, G. 1972. Miristicáceas do Estado do Paraná. Boletim do Museu Botânico Municipal 4: 1-4. 
Machado, O. X. B. 1949. Bicuíba. Virola bicuhyba (Schott) Warb. Contribuição ao estudo das plantas medicinais do Brasil. Rodriguésia 24: 53-78.

Mello, E.C. 1950. Estudo dendrológico de essências florestais do Parque Nacional de Itatiaia e os caracteres anatômicos de seus lenhos. Boletim do Serviço Florestal. Parque Nacional de Itatiaia 2: 1-174.

Reitz. P.R. 1968. Miristicáceas. Flora Ilustrada Catarinense. Fasc. MIRI: 1-15. Herbário Barbosa Rodrigues, Itajaí.

Rizzini, C.T. 1971. Árvores e madeiras úteis do Brasil - Manual de dendrologia brasileira Editora E. Blücher Lıda. e Editora da Universidade de São Paulo. São Paulo.

Rodrigues, W. A. 1980. Revisão taxonômica das espécies de Virola Aublet (Myristicaceae) do Brasil. Acta Amazonica, Supl. 10(1): I-127.

Schott. H. W. 1823. Myristica oleifera Schott interim. In I. Oken (ed.). Isis oder Encyclopädische Zeitung 12-13: 1050 .

Schott, H. W. 1827. Myristica bicuhyba Schott. In C. Sprengel (ed.). Systema vegetabilium. Appendix (Curae Posteriores), 16 ed.. 4(2): 409.

Schultes. R. E. \& Holmstedt. 1971. De plantis toxicariis e mundo novo tropicale commentationes. VIII. Miscellaneous notes on Myristicaceous plants of South America. Lloydia 34(1): 61-79.

Smith. A.C. \& Woodhouse, R.P.1937. The American species of Myristicaceae. Brittonia 2(5): 393-510.

Uphof. J. C. 1959. Myristicaceae Pp. 177-220. In A. Engler \& Prantl (eds.), Die Natürlichen Pflanzenfamilien 17a II. $2^{a} \mathrm{ed}$. Duncker \& Humblot, Berlin.

Warburg. O. 1897. Monographic der Myristicaceen. Nova Acta Physico-medica Academiae Caesareae Leopoldino-Carolinae Naturae Curiosorum Vratislaviae et Bonnae 68: 1-680.

Wilde. W. J. J. O. de. 1991. The genera of Myristicaceae as distinguished by their inflorescences, and the description of a new genus. Bicuiba. Beiträge zur Biologie der Pflanzen 66: 95-125. 